\title{
Research on the Establishment of Financial Internal Control System of
}

\section{Science Institutions}

\author{
Junji Zhang ${ }^{1}$, Jian Feng ${ }^{1}$ \\ ${ }^{1}$ Institute of Geo-mechanics, CAGs, Beijing, 100081
}

KEYWORDS: Financial Internal Control; Science Institutions; Risk Management

\begin{abstract}
With the growing strength of China's economy, the state also increased the financial institutions capital investment, but also the reform of the financial management system, however, under the old system of management institutions, due to the lack of internal control methods and awareness of risk management, financial resources utilization efficiency is low, the use of funds and monitoring processes there are loopholes in management processes and institutions in particular, low control efficiency of the financial aspects, or even illegal use of cash, embezzlement, waste and other issues, it would greatly increase of financial pressure, slow the development of social and public utilities, so that the quality of public services and social security are not properly reflected. Therefore, to improve the level of internal control and management of institutions to improve risk management among institutions, and increase financial management system reform has become our institutions and public services, the development of an important issue.
\end{abstract}

\section{Introduction}

Eleventh Five-Year "period, the country's total public expenditure finance reached 31.9 trillion, spending on health, education, culture, social security and employment reached 1.49 trillion, 4.45 trillion, 560 billion and 33,300 billion in 2011 to make arrangements for central government spending in health care and people's lives are directly related to education, housing, security, social security and employment, and cultural aspects of the total 1.050992 trillion, an increase of $18.1 \%$ over 2010. aspects of science, education the funds are mainly used to support financial institutions to carry out public services, in recent years more attention to the effectiveness of national institutions expenditure is correspondingly increased investment of financial resources, in addition to the introduction, the budget, the state-owned assets on centralized treasury payment management system provides the State also increased the targeted financial benefits of funds of audit inspection, such as state-owned assets of the institution to conduct a comprehensive inventory of "small treasuries" special treatment activities, which allow inspections of financial management tends to be more scientific, fine. in addition, the social structure lag restricted the rapid development of the economy, the government needs to strengthen guidance enterprises, enhance the ability to serve the community, especially the commitment to social functions, engaged in public service institutions must be limited optimize the allocation of resources, through effective internal controls to enhance the management level, in the pursuit of social benefits while ensuring the rational use of financial funds, in order to better participate in public service. in recent years, scientific institutions and economic financial management level business compliance, gradually increase the legitimacy of the whole. However, some institutions still imperfect management system design, the implementation 
is not in place, supervised the wrapping and so on. some of the specific performance per unit of economic mismanagement, lack of internal controls, resulting in a large number of assets losses and waste; some units use of false invoices to conceal non-compliance expenditures, or obtain funds, set up a "small treasuries"; and more serious things and some people use "IOUs arrived library", a fictional business corruption etc. misappropriation of financial resources. in addition, free lending bank accounts, illegal disposal of state assets without the approval of the higher level of foreign economic contracts signed without such phenomena also occur. Therefore, it is necessary to establish and improve internal control system to plug the loopholes, remove hidden dangers, the risk of major economic activities of scientific institutions for effective prevention.

\section{Institutions Financial Management Problems}

Internal accounting controls content: physical assets, foreign investment, monetary funds, procurement and payment, project, financing, cost control, sales and receivables, guarantees and other economic activities. The main control object of internal accounting control include: control, risk control, control electronics and information technology controls, incompatible positions budget authorization and approval of control, internal control reports. These methods and systems are improving efficiency in the use of funds to ensure the legitimate security institutions property of great significance. However, since the institution is in the planned economy era has produced, it is mainly financed by the national government finance, but also must be submitted in accordance with the provisions of the expenditure, therefore, can only play on the internal accounting management institutions in the government sector action, and cannot play a role in the market competition. Internal Accounting Control irrational, inefficient due to the limitations of their mechanisms and institutions caused.

Original documents occur in specific economic activities, it is a valid certificate of financial responsibility, this proof certificate for the relevant economic business people after fill in the certificate form, the economic activity has occurred or is completed. Related laws is also clear that the economy must truthfully fill transact business when the original documents acquired; the project should be completed in the original documents to fill out, cannot be missing; foreign original documents should be stamped with official seal, and individuals all original documents must be filled in staff signature or seal; once the original documents fill in the content has been altered, the original documents will be regarded as invalid credentials. The original document issued units should be corrected or re-opening note of the error credentials. Unit complete original documents issued corrections work, the last place in the correct cover seal issued by the unit; if the amount of bad situations occur original documents, unauthorized individuals cannot be modified, you must make the certificate issued by the correct amount of units issued again original documents. Under normal circumstances, the original issuing units see drama liable to be issued again and correct incorrect original documents.

Many institutions of internal accounting control system is defective, assets requisitioned, no comprehensive record keeping or accounting, inventory system is not on a regular basis, after buy assets, after several turnover, they suddenly disappear. Some units of goods and projects not through government procurement and bidding, own procurement, public transparency is not enough; asset management extensive, those responsible are not implemented, long-term inventory, over time the account there was dead; some units do not follow state regulations to be scrapped, the sale of state property, causing heavy property damage. From the audit scandal disclosed each year, there are numerous examples to show the status quo unsafe state assets. 
Some institutions have a problem, fixed assets accounting, financial and accounting information appears false in fixed assets reflects changes in time, wrong note, the omission, the result is posted, real different. The other is in the account to show only the total value of fixed assets, and did not include a breakdown of the number of records in kind and value, book value of the assets can not be a complete explanation of the physical situation; in some institutions still remember Ledger have not used fixed assets, which became off-balance assets; and some units will not have occurred to the accounting records transferred assets, and the assets, although the occurrence of major, but the unit did not go through the relevant procedures.

\section{Financial Management System in Institutions}

Accordance with the "basic norms of internal control accounting control" provisions and "Accounting Law", the people responsible for an accounting unit as the first responsibility of the main work, the main unit of accounting reports is really responsible for ensuring that "the main responsibility for the first complete construction and internal control system "consciousness, but also the need to strengthen the relevant institutions responsible for training in leadership and internal control aspects. Thus, accounting management institutions at all levels and relevant departments should be at different times in different batches and types of primary and secondary budget units please principal leaders of relevant seminars to discuss, learn, so that they can master the basics of internal control, improve the internal control system constructive awareness and develop their good sense, to improve the organization's internal control environment.

An important reason for public institutions, severely restricting its operating results and internal control system of the program budget is the accounting unit of touch. So, we want to enhance the internal capacity and institutions for the rational use of finances and lay a solid foundation. In addition, institutions must also strengthen the effectiveness of the control system of accounting, and the importance of improving basic accounting institutions. Financial institutions need the relevant accounting workers and institutions to regulate and training services, and establish the appropriate test, reward and punishment mechanism.

Accounting Personnel System A market economy requires consistent internal financial management system came into being, such a system would present community level and subordinate units operate as a whole, in accordance with the competition rules of market economy, so that resources (including financial, material and human) to obtain the optimum configuration as a whole. At the same time, ready to control, supervise this arrangement work, and to take measures against the problems which can be possible to prevent operational problem. Appointment System is a new management accounting, applicable to the original "separation of powers" of the modern enterprise system, this model will be grafted into the scientific institutions, can play a role similar to the. Entered the 21st century, a department of the province began to implement the provincial government departments and their subordinate units pilot accountant accreditation system, and the establishment of specialized agencies in these pilot units, and accounting personnel appointed directly managed by the Department of Finance, unified delegation. Appointment System is a monitoring, control system, which is the subject of accounting personnel management major government accounting dispatched; monitoring control object is the state-owned institutions of funds, use of assets and financial situation. Particularly in the financial allocation of administrative organs, institutions such public entities in the implementation of accounting appointment system is common international practice, in line with the direction of fiscal reforms, in line with the socialist market economy, and to strengthen financial management, public finance framework, the gradual the implementation of a unified treasury receipt and payment system foundation. A huge change in 
accounting management system is implemented appointed delegate accounting system, this mechanism allows the quality of accounting information can be improved, while also strengthening the normative basis of accounting work; you can increase revenue and control spending, strengthen budget control of foreign capital, it is possible to effectively control wastage, rectify the "three arbitrary" and kangaroo "treasury" and other issues.

To develop a scientific and rational planning must be based on the level of demand and possibilities, refer to the expectations of the development sector, the responsibility to fulfill and take full account of the existing assets. Determined on the basis of financial stage does not exceed the level of development and affordability of the stages of development and the direction of their related businesses; to make a clear judgment on the details of the special expenditure of infrastructure projects, large equipment, machinery procurement, and establish a sound project library . At the same time, the financial sector must be strengthened at the time of preparation and implementation of the various sectors of financial capital budget for the purchase of special funds and carry out the project approval. Secondly, the fixed asset is its value in use to support the institutions work properly. Finally, the institutions to improve management efficiency in the use of fixed assets by state-owned assets, the rational allocation, fixed assets with tasks and matching efficiency and to develop a series of measures to avoid waste of assets.

Legal concepts and moral accounting staff needs to be improved. "Accounting Law" expressly provided for false accounting and financial personnel making false behavior in the case of its superior inspired respective penalties. State Council financial departments above the county level and the relevant financial institution plus the management of the national accounting work of the judiciary as the institution should increase the punishment for such acts. At the same time, strengthen the rule of law but also a variety of ways so that accounting personnel, various forms of learning to strengthen their own moral construction, but the formation of society "fake" good work style. Accountants must maintain a serious and responsible attitude, objective and impartial, comply with professional ethics, principles, honesty, not forged, altered accounting documents, books, newspaper or submission of false financial statements. Also relevant departments need to recommend a complete set of accounting professional ethics, and increase the punishment of illegal workers, professional behavior in order to supervise and manage the accounting staff.

\section{Conclusion}

Internal control is an originally produced as companies there is a control and management measures to prevent the problem in the daily production and management activities, which itself is set up for businesses, but the institution as a non-profit organization, there are many and the same enterprise business management processes, such as: budget management, procurement management, capital expenditure activities, construction project management, debt management, economic contract management, financial management units of the problems put forward recommendations from major accounting control , financial management control and operational control presented in these three areas.

\section{Reference:}

[1] Tierney C; E Kearney; R Fernandez, Audit Federal Financial Controls: Sooner Rather Than Late Would Sarbanes-Oxley Benefits Federal Financial Management, 2004 (04).

[2] OMB Revisions to OMB Circular A-123, Management's Responsibility for Internal Control 2004. 
[3] INTOSAI, Guidelines for Internal Control Standards for the Public Sector 2004.

[4] Internal control: Improvements needed in SEC's accounting and operational procedures, 2007. 